\title{
Facilitating Computer-Supported Collaborative Learning with Question- Asking Scripting Activity and its Effects on Students' Conceptual Understanding and Critical Thinking in Science
}

\author{
Hazel Joyce M. Ramirez \\ Corresponding author: hmramirez@up.edu.ph \\ University of the Philippines Rural High School, College of Arts and Sciences, University of the Philippines \\ Los Baños, Laguna, 4031, Philippines
}

\begin{abstract}
Computer-supported collaborative learning (CSCL) provides an environment that enhances social interaction and shared knowledge construction among students. However, limited research has examined CSCL reinforced by question-asking scripting activity. This research investigated the effects of CSCL with question-asking scripting activity on the development of conceptual understanding and critical thinking in science. Moreover, the research design was a three-group pre-test-post-test quasi-experimental study in which the research sample were 106 Grade 7 students. The only difference between the control and the experimental groups was the exposure to CSCL. The experimental groups were exposed to CSCL approaches: one without scripting while one was exposed with question-asking scripting activity. Results revealed that CSCL approaches significantly affected the development of students' conceptual understanding and critical thinking. Specifically, CSCL with scripting stimulated more intellectual discussion which allowed learners to deepen lesson comprehension and improve their critical thinking skills. Insights on the innovations through technology integration, collaborative inquiry learning, and questionasking activity to enhance science education were also discussed. The findings of this study have important implications for future practice.
\end{abstract}

Keywords: computer-supported collaborative learning, conceptual understanding, critical thinking, student-generated questions, scripts

\section{Introduction}

The 21st century pedagogy involves reinventing the teaching and learning process that seeks to promote and develop the 21 st century learning skills, namely: critical thinking, collaboration, creativity, and communication (Partnership for 21st century learning, 2015). The Partnership for 21st Century Skills (P21) is the collaboration of several education stakeholders and aims to provide the framework containing the skills needed in the 21st century. P21 emphasises that the integration of technology is needed in order to promote an innovative learning environment, in which technology is regarded as one of the tools to develop 21st century learning skills (Lapinid, 2014; Partnership for 21st century learning, 2015). Indeed, the integration of technological tools as instructional material is fast becoming a key instrument in enhancing learning (Cheung, Slavin, Kim, \& Lake, 2017; Sari, Pektas, Celik, \& Kirindi, 2019; Shin, Kim, \& Jung, 2018; Yang, Jen, Chang, \& Yeh, 2018). When utilised appropriately, technology together with student-centred pedagogy could be a powerful instrument to enrich and deepen the skills and competencies of the students. 
Specifically, in the present study, the courseware was the multimedia-based instruction material utilised in a computer-supported collaborative learning environment. The courseware modules were new learning platforms in the school wherein the teacher-researcher used the courseware as part of the intervention. The courseware in the study is a locally made learning material and has integrated some contextualised learning elements such as the examples and graphic background setting. Several studies have shown that the use of courseware in instruction has significant effects in the learning process due to its interface design and interactivity features (Efendioglu, 2012; Ercan, Bilen, \& Ural, 2016; Tsai, 2012).

Nevertheless, the integration of technology alone is not an assurance of improved learning experience. This should be coupled with innovative teaching strategies in order to help students to have a deeper sense of various phenomena. In this light, computer-supported collaborative learning involves the infusion of technology together with collaborative inquiry which allows students to learn together towards a shared goal using a computer. A number of studies revealed the positive effects of computer-supported collaborative learning (CSCL) in the learning process (Miller \& Hadwin, 2015; Shin et al., 2018; Vogel, Wecker, Kollar, \& Fischer, 2016). In this research, CSCL is further reinforced by scripting activity that involves student-generated questions. Utilising a contextualised learning approach with educational technology has the affordance to accelerate human capital development by giving opportunities for students to weave their daily life experiences with scientific concepts, thus, increasing the authenticity of learning and making science a relevant and coherent discipline to life. Particularly, this research aimed to investigate the effects of CSCL enhanced by question-asking activity on students' conceptual understanding and critical thinking in science.

\section{Literature Review}

\section{Computer-Supported Collaborative Learning}

CSCL is an approach where students work together in completing computer-aided tasks that encourage social interaction and shared knowledge construction among learners (Shukor, Tasir, Van der Meijden, \& Harun, 2014). This learning approach gives opportunities for students to engage in a collaborative learning process by providing their insights to their peers and performing activities that lead to the fulfillment of certain tasks. Moreover, this pedagogical approach also promotes a shared understanding of the lesson wherein concepts are learned from several perspectives, hence, knowledge building becomes more meaningful and authentic (Chan, Lam, \& Leung, 2012; Kirschner \& Erkens, 2013; Miller \& Hadwin, 2015; Stahl, Koschman, \& Suthers, 2006).

However, learning collaboratively may also have drawbacks especially when there are unaddressed concerns and unshared messages which could lessen the quality of interactions in learning (Shin et al., 2018). The foremost scaffold in CSCL is a collaboration script, simply known as script, which facilitates collaboration by sequencing the activities, structuring the interaction, and guiding the discussion (Kirschner \& Erkens, 2013; Su-Chi, Ying-Shao, \& Wei, 2016; Vogel et al., 2016). In this study, the script is aligned with the central conceptual framework of a script as proposed by Kollar, Fischer, and Heese (2006). The parts of the script are "objectives", "activities", "sequencing", "roles", and "types of representation". Essentially, the script orchestrates the collaborative inquiry by assigning roles and directing the activities.

Particularly, "fading script" was employed in this study. In fading script, initially, all components were incorporated in the script which allowed students to acquire and practice the necessary skills to perform the activity. Eventually, a certain part of the script was withdrawn 
in order to provide avenues for students to apply the acquired skills. Through this, it can be inferred that learners were able to internalise the process and integrate information and skills needed to accomplish the task. Previous studies revealed that the utilisation of fading scripts can result in significant effects in learning such as improved scientific inquiry, transfer of learning, and conceptual understanding (Bouyias \& Demetriadias, 2012; Su-Chi et al., 2016).

Furthermore, the scripting in this study specifically integrated question-asking activity that could provide a learning environment that nurtures higher order thinking skills (Chin \& Osborne, 2010; Huang, Lederman, \& Cai, 2017). Specifically, Cuccio-Schirripa and Steiner pointed out that "questioning is one of the thinking processing skills which is structurally embedded in the thinking operation of critical thinking, creative thinking, and problem solving" (as cited in Hofstein, Navon, Kipnis, \& Mamlok-Naaman, 2005, p. 210). This is made possible since the process of questioning entails revisiting prior conceptions, searching relevant ideas, investigating interconnections between and among concepts, refining alternative conceptions, and evaluating reasoning (Chinn, 2002; Lee, 2015). Additionally, the student-generated questions provide means to assess students' understanding of the lesson and their ability to extend the concepts learned (Huang et al., 2017). In the context of the present study, this is further validated quantitatively by measuring the effects of the intervention through the use of assessments that measure students' conceptual understanding and critical thinking. Furthermore, questioning skill is not limited to problem-solving, critical thinking skills, and creative skills. It is also associated with communication and collaboration skills since questioning is an important skill in social functioning through discussion of ideas with peers (Kaberman \& Dori, 2009). Therefore, it can be inferred that questioning activity is a driving force in the development of $21^{\text {st }}$ century learning skills.

\section{Conceptual Understanding and Critical Thinking}

Conceptual understanding refers to students' conception, application, and analysis of the lessons taught (Su-Chi et al., 2016). It is considered as one of the measures of student achievement since it is a "productive means of accessing and framing knowledge in the curriculum" (Ministry of Education, 2009, p. 7). Specifically, the integration of technology in education is considered as one of the tools to facilitate the improvement of students' conceptual understanding (Efendioglu, 2012; Ercan et al., 2016; Sari, Hassan, Güven, \& Sen, 2017; Tsai, 2012). It helps reduce the abstractness of science concepts through multiple inputs to process information and presents the lessons in an interesting manner (Ercan et al., 2016; Ryoo \& Bedell, 2017). Despite the benefits of ICT as a means to visualise information, there are reported concerns in utilising such multimedia instructional materials such as complexity of features as well as rapid transitions of concepts and visuals which could then render heavy cognitive load (Ryoo \& Linn, 2012; Yang et al., 2018). It is for this reason that the learning environment in the present study is facilitated by scripting activity that enhances the concepts learned from dynamic visualisation of varied geological phenomena.

Aside from conceptual understanding, it is also important to assess critical thinking skills of the students. Question-asking as one of the processes of inquiry learning is the essence of science learning and is closely associated with critical thinking (Lee, 2015). Critical thinking is considered as a higher order thinking skill that involves the process of actively conceptualising, applying, analysing, synthesising, and/or evaluating information (Mandernach, 2006). The development of critical thinking is paramount in education since it is one of the 21st century learning skills needed for life-long learning (P21, 2015). The integration of technology in education can be one of the means to provide more opportunities 
to foster the development of critical thinking by letting students explore, investigate, create and discover principles, and make generalisations and connections (Lapinid, 2014).

Although previous researchers have investigated the effects of CSCL in conceptual understanding and critical thinking, few studies have explored the confluent effects of CSCL and question-asking scripting activity on these variables. In this light, this study was directed to address this research gap. This research contributed to the growing field of CSCL, specifically how the learning approach, enhanced with question-asking scripting activity, facilitated the development of students' conceptual understanding and critical thinking.

\section{Research Questions}

This research examined the effects of computer-supported collaborative learning enhanced with question-asking scripting activity. Specifically, this study sought to answer the following questions:

1. Do students exposed to CSCL teaching approaches have better scores in the Earth Science Conceptual Understanding Test than students exposed to a conventional teaching approach?

2. Does CSCL teaching approaches significantly impact the improvement of students' critical thinking?

\section{Methodology}

\section{Research Design}

The research design of this study was a pre-test-post-test quasi-experimental study. The designation of the class to either experimental or control group was randomly determined. Particularly, this research involved the collection of both quantitative and qualitative data, but the latter plays a supplemental role within the overall design (Creswell, 2003). Specifically, this study utilised three intact heterogeneous classes. One class was considered as the control group, Conventional Teaching Approach (CTA). On the other hand, two classes were considered as experimental groups and were named Computer-Supported Collaborative Learning Teaching Approach (CSCLTA) and Question-Asking Scripting Activity in Computer-Supported Collaborative Learning Teaching Approach (QASACSCLTA). All classes were handled by the teacher-researcher wherein parallel but differentiated lesson flow and learning materials were utilised. Furthermore, the duration of the research implementation took almost two months.

\section{Research Sample}

The research sample involved 106 Grade 7 students divided into three classes. Each class had approximately the same number of male and female students. Additionally, each class was subdivided into groups composed of three members. The age range of the participants of the study is 12-13 years old. Students had already taken earth science subjects and had a good grasp on the use of a computer from their classes in the elementary level which were considered as prerequisite skills. Table 1 presents a profile of the research sample. 
Table 1. Profile of the Research Sample

\begin{tabular}{lllll}
\hline Group & $\begin{array}{l}\text { Number of } \\
\text { Students }\end{array}$ & Sex & & $\begin{array}{l}\text { Average Age } \\
\text { (in years) }\end{array}$ \\
\cline { 3 - 4 } & 35 & Male & Female & 12.12 \\
QASACSCLTA & 35 & 15 & 20 & 12.39 \\
CSCLTA & 36 & 16 & 19 & 12.45 \\
CTA & & 20 & \\
\hline
\end{tabular}

The researcher sought permission from the parents of the research sample through a letter informing them about the study and asking their consent for their children's involvement in the study including the engagement in the computer-supported collaborative learning as well as engagement in the scripting activity and in the focus group discussions. The letter has been approved by the principal as the overall head of the school who is tasked to ensure that necessary ethical standards are being implemented in various stakeholders of the school. The researchers assured that parents can freely decline with no prejudice to their children in case they decided not to participate. All the parents expressed their willingness to participate in the study.

\section{Research Instruments}

The Earth Science Conceptual Understanding Test (ESCUT) was a researcher-made test, composed of 30 items, intended to measure students' comprehension, analysis, and application of selected earth science topics such as earthquakes, volcanoes, and mountains. There were varying levels of questions based on Bloom's Taxonomy wherein the questions were presented in a multiple-choice test type. ESCUT underwent validation through a panel of experts in the field of earth science education. The experts evaluated whether the questions matched their corresponding level in Bloom's Taxonomy, content validity of the questions, face validity of the questionnaire, and suitability of the questionnaire to the students. Consequently, ESCUT was pilot tested. Based on the reliability analysis, ESCUT has a good internal consistency and acceptable value of Cronbach's alpha, .70.

The Critical Thinking Scale (CTS), a 7-point Likert type scale, was obtained from the Motivated Strategies for Learning Questionnaire developed by Pintrich, Smit, Gracia, and McKeachie, (1991). According to Pintrich et al. (1991), the statements in the Critical Thinking Scale refer to the "degree to which students report applying previous knowledge to new situations in order to solve problems, reach decisions, or make critical evaluation with respect to standards of excellence" (p. 13). Additionally, CTS has a high reliability coefficient with Cronbach's alpha of .80 .

\section{Intervention}

The teacher-researcher handled the three heterogeneous intact classes. Particularly, 5Es (Engage, Explore, Explain, Elaborate, and Evaluate) learning cycle is the lesson delivery utilised in all classes. The control group was exposed to a conventional teaching approach. On the other hand, the only difference between the control and the experimental groups was the exposure to Computer-Supported Collaborative Teaching Approaches. Meanwhile, the engagement in scripting, which primarily involved question-asking activity, distinguished the two experimental groups. In this study, courseware and the scripts were the learning materials integrated in the computer-supported collaborative learning setting.

The courseware utilised in this study was developed by the Department of Science and Technology in partnership with the Department of Education and two premier universities in 
the country in the field of education. The characters, places, and other features used in this courseware module were contextualised in the Philippine setting in order to increase the familiarity of the context of the content which could eventually lead to more sharing of ideas during discussion and greater appreciation of the country. Every courseware learning module started with a simple activity that initially engaged the students in the learning process. Subsequently, this was followed by discussion of the concepts which contained daily life examples and real-life problems, hence, making concepts more relevant. Eventually, each learning module unfolded through the application and assessment of the lesson.

In this research, the scripting activity facilitated the engagement among learners in a group. The objectives of the scripting activity were to enhance the learning process by the creation of new questions based on pre-identified questions from the courseware as well as the elaboration of the created questions through proposing answers to the questions and synthesising information. Additionally, these learning activities in scripting were encapsulated in a worksheet where students wrote their answers to accomplish the task. In order to ensure a dynamic interaction, each member of the group had specific roles such as (1) information giver who formulated new questions, (2) elaborator who provided answers to the created questions, and (3) recorder who synthesised information from the courseware and the proposed answer. Moreover, the team roles were redistributed among the members of the group in every learning cycle so that each student had the opportunity to portray each team role in order to contribute to the collaborative discussion of the lesson. Figure 1 illustrates the sample worksheet utilised during the scripting activity. In each scripting activity, there were two identified questions from the courseware in which the group created two questions in each identified question.

III. Activity
\begin{tabular}{|l|c|c|c|c|}
\hline $\begin{array}{c}\text { Given questions } \\
\text { (What are the } \\
\text { given questions?) }\end{array}$ & $\begin{array}{c}\text { Additional Insights } \\
\text { (What are the insights from } \\
\text { the courseware and during } \\
\text { the discussion which are } \\
\text { related to this question? }\end{array}$ & $\begin{array}{c}\text { Created Questions } \\
\text { (What new questions can } \\
\text { you give in order to offer } \\
\text { other insights in the given } \\
\text { questions?) }\end{array}$ & $\begin{array}{c}\text { Proposed Answer } \\
\text { (What could be the } \\
\text { possible answer in the } \\
\text { identified new question?) }\end{array}$ & $\begin{array}{c}\text { Combination of Information } \\
\text { (How can you relate the } \\
\text { information from the proposed } \\
\text { answers and other insights) }\end{array}$ \\
\hline $\begin{array}{l}\text { What causes an } \\
\text { earthquake? }\end{array}$ & & 1. & & \\
\cline { 3 - 5 } & 2. & & & \\
\hline
\end{tabular}

Figure 1. Sample part of the script during the question-asking scripting activity

\section{Data Gathering Procedure}

Prior to the conduct of the study, the researcher administered the Earth Science Conceptual Understanding Test and Critical Thinking Scale as pre-test. Together with the administration of the pre-test of instruments, the researcher conducted an orientation of the courseware and its features. In the following class sessions, the teacher-researcher implemented the research intervention. There were six learning cycles which covered topics on earthquakes, volcanoes, and mountains. During the implementation, the students were asked to write in their journal the learning experiences in every learning cycle. Moreover, the students also engaged in focus group discussions regarding their insights in the activities of the intervention, specifically the integration of the courseware and the question-asking scripting activity. This was facilitated by the teacher and the conversation was audio recorded. There were two focus group discussions 
implemented after the third and sixth learning cycle. One representative from each group participated in focus group discussions. There were two subgroups for each focus discussion wherein each subgroup was composed of 6 representatives from different groups. The questions in the focus group discussion were aligned with the research questions in order to obtain additional insights about the intervention. The conversation was transcribed by the researcher. Lastly, after the implementation of the intervention, ESCUT and CTS were administered as post-test. Figure 2 illustrates the data gathering procedure employed in the research.

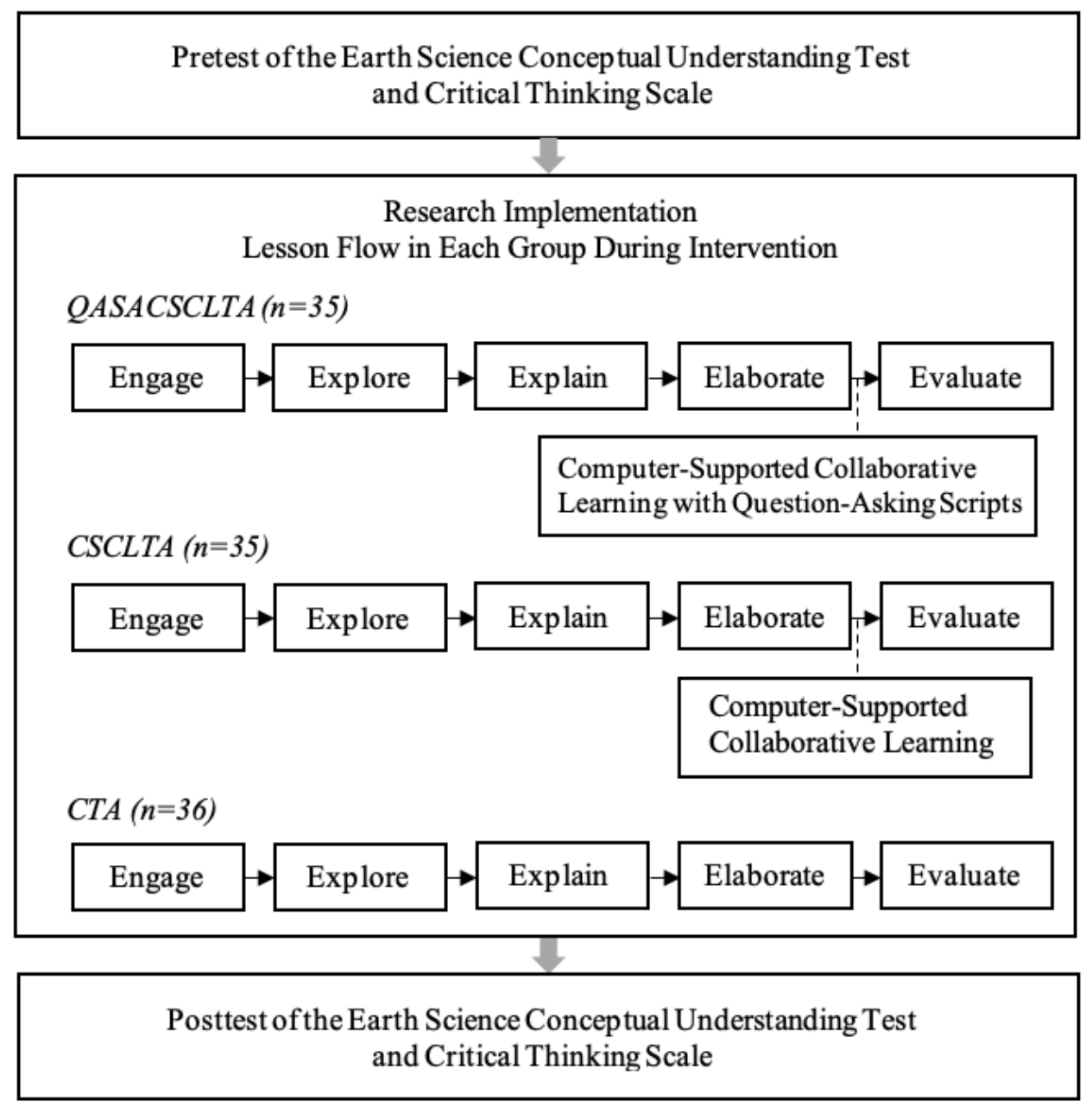

\section{Figure 2. The research procedure utilized in the study}

\section{Data Analysis Procedure}

This research gathered both quantitative and qualitative data. Analysis of Variance (ANOVA) was performed on the mean pre-test scores of ESCUT and CTS to determine the initial comparability of control and experimental groups and the effect of the intervention on students' conceptual understanding and critical thinking, respectively. The qualitative data of the research were obtained from the student journals and results of focus group discussion. These qualitative data were examined and were used to support the quantitative data. Specifically, the journal entries and the transcripts from the focus group discussion were categorised into themes to facilitate analysis of results. 


\section{Results}

\section{Initial Comparability in Conceptual Understanding}

During the pre-test, students in the three classes, QASACSCLTA, CSCLTA, and CTA, had a mean score of $M=14.05(S D=2.70)$ in ESCUT. Moreover, to establish the comparability of conceptual understanding prior to the intervention, a one-way ANOVA was conducted on the ESCUT pre-test scores. The Levene's test for homogeneity of variances indicated equal variances, $F(2,103)=1.597, p=.104$. The ANOVA showed statistically insignificant difference among the groups, $F(2,103)=3.041, p=.066$. This implied that all the groups had comparable conceptual understanding prior to the intervention.

\section{Effects of Teaching Approaches on Conceptual Understanding}

After the implementation of the intervention, it was found that there was an increase in posttest scores of the students wherein the mean score was $M=18.32(S D=2.45)$. Table 2 compares the pre-test and post-test scores of the students.

Table 2. Mean Earth Science Conceptual Understanding Test Pre-test and Post-test Scores by Teaching Approach

\begin{tabular}{llccc}
\hline Group & Pre-test & \multicolumn{3}{c}{ Post-test } \\
\cline { 2 - 5 } & Mean & SD & Mean & SD \\
\cline { 2 - 5 } QASACSCLTA & 14.77 & 2.37 & 18.91 & 2.41 \\
CSCLTA & 13.51 & 2.88 & 18.57 & 1.94 \\
CTA & 13.86 & 2.73 & 17.50 & 2.77 \\
\hline
\end{tabular}

The preliminary Levene's test indicated equal variances, $F(2,103)=1.491, p=.115$. Satisfying this assumption, the analysis proceeded to one-way analysis of variance. Subsequently, as can be seen in Table 3, ANOVA showed that there was a significant difference in the students' conceptual understanding, $F(2,103)=3.360, p=.020$. From this, it can be inferred that computer-supported collaborative learning approaches significantly influenced the improvement of students' conceptual understanding in earth science.

Table 3. Analysis of Variance of the Earth Science Conceptual Understanding Post-test Scores

\begin{tabular}{llllll}
\hline & Sum of Squares & df & Mean Square & F & $p$ (one-tailed) \\
\hline Between groups & 38.78 & 2 & 19.39 & 3.360 & $.020^{*}$ \\
Within groups & 594.31 & 103 & 5.77 & & \\
Total & 633.09 & 105 & & & \\
$* p<.05$ & & & & & \\
\end{tabular}

Since ANOVA provides information on the overall difference between treatments, it is worth investigating which pair of groups showed a significant difference. Consequently, this could offer essential findings on which treatment showed significant results. Post hoc comparison using Tukey's Honestly Significance Difference (HSD) Test was administered in order to determine which pair of groups showed significant difference by comparing the post-test means of the groups. Results indicated that there was a significant difference between QASACSCLTA and CTA $(M D=1.414, p=.020)$. However, the mean post-test score of QASACSCLTA was not significantly different from the CSCLTA $(M D=.343, p=.411)$ and the mean post-test score of CSCLTA was not significantly different from CTA $(M D=1.071, p=.075)$. This suggested 
that CSCL coupled with question-asking scripting activity had a statistically significant effect in developing the conceptual understanding of students.

\section{Initial Comparability in Critical Thinking}

The overall mean pre-test score of students in the Critical Thinking Scale was $M=4.58(S D=$ 1.21). To determine the initial comparability of groups in terms of critical thinking, a one-way ANOVA was performed on the CTS pre-test scores. Initially, the assumption of homogeneity was investigated using Levene's test and the result indicated that variances were assumed to be equal, $F(2,103)=.154, p=.426$. At .05 level of significance, ANOVA revealed that the mean pre-test scores in CTS was insignificant, $F(2,103)=1.482, p=.116$. which suggested that QASACSCLTA, CSCLTA, and CTA had comparable critical thinking before the implementation of the intervention.

\section{Effects of Teaching Approaches on Critical Thinking}

The comparison of the pre-test and post-test scores in the Critical Thinking Scale is shown in Table 4. Notably, the overall mean post-test score in the CTS was higher compared to the mean pre-test score, $M=5.16(S D=1.00)$. Furthermore, one-way ANOVA was employed to determine whether there was a significant difference among groups. Levene's test showed an insignificant value, $F(2,103)=.006, p=.497$, which indicated that the assumption of homogeneity was not violated. Consequently, at .05 level of significance, as can be seen in Table 5, ANOVA revealed that the effect of the teaching approach on critical thinking was significant, $F(2,103)=3.016, p=.027$. This result implied that the significant increase in students' critical thinking can be attributed to the effect of the computer-supported collaborative learning teaching approaches.

Table 4. Mean Critical Thinking Scale Post-test Scores by Teaching Approach

\begin{tabular}{llccc}
\hline Group & Pre-test & \multicolumn{3}{c}{ Post-test } \\
\cline { 2 - 5 } & Mean & SD & Mean & SD \\
\cline { 2 - 5 } QASACSCLTA & 4.74 & 1.14 & 5.47 & .99 \\
CSCLTA & 4.71 & 1.25 & 5.13 & .97 \\
CTA & 4.30 & 1.23 & 4.90 & .97 \\
\hline
\end{tabular}

Table 5. Analysis of Variance of the Critical Thinking Scale Post-test Scores

\begin{tabular}{llllll}
\hline & Sum of Squares & df & Mean Square & F & $p$ (one-tailed) \\
\hline Between groups & 5.81 & 2 & 2.91 & 3.016 & $.027^{*}$ \\
Within groups & 99.16 & 103 & .96 & & \\
Total & 104.97 & 105 & & & \\
$* p<.05$ & & & & & \\
\hline
\end{tabular}

Post hoc analysis using Tukey's HSD test was employed to the post-test score to determine which pair of groups showed a significant difference. Results showed that there was a significant difference between QASACSCLTA and CTA $(M D=.569, p=.022)$. However, the mean post-test score of CTA was not significantly different from the CSCLTA $(M D=.226, p$ $=.299)$ as well as between QASACSCLTA and CSCLTA $(M D=.343, p=.157)$. This showed that computer-supported collaborative learning with question-asking scripting activity (QASACSCLTA) positively affected the development of critical thinking of students. 
Qualitative data were obtained in the study to further support the analysis of the results. Table 6 provides the snippets of the emerging themes on the perspectives of the students regarding the benefits of the intervention as reflected in the students' journals and focus group discussion.

Table 6. Sample responses of the students regarding the perceived benefits of the courseware and the question-asking scripting activity

\begin{tabular}{ll}
\hline Emerging Themes & Sample Responses \\
\hline $\begin{array}{l}\text { Reinforces better } \\
\text { understanding of the } \\
\text { lesson }\end{array}$ & $\begin{array}{l}\text { CSCLTA Student 40: "The courseware was so informative, and it } \\
\text { helped us in correcting our mistakes in understanding the topic." } \\
\\
\text { QASACSCLTA Student 22: "The positive thing that happened } \\
\text { during the activity is we understand more the lesson and the lesson } \\
\text { was discussed well organized." }\end{array}$ \\
$\begin{array}{ll}\text { Provides effective } \\
\text { and varied visuals }\end{array}$ & $\begin{array}{l}\text { CSCLTA Student 26: "The animation is very nice, and the puzzles } \\
\text { are very helpful." }\end{array}$ \\
& $\begin{array}{l}\text { QASACSCLTA Student 33: "The courseware helped me in } \\
\text { learning because not only did the courseware taught us about the } \\
\text { lesson, but it also gave us a visual representation which helped us } \\
\text { imagine the lessons being taught." }\end{array}$ \\
$\begin{array}{l}\text { Promotes } \\
\text { development of } \\
\text { thinking process } \\
\text { skills }\end{array}$ & $\begin{array}{l}\text { CSCLTA Student 19: "The courseware helped me by asking } \\
\text { questions." }\end{array}$ \\
& $\begin{array}{l}\text { QASACSCLTA Student 33: "The question asking did a big role in } \\
\text { our learning. It makes us curious over things and makes us work } \\
\text { hard and diligently find answer to it." }\end{array}$
\end{tabular}

\section{Discussion}

This study aimed to determine the effects of computer-supported collaborative teaching approaches, especially the integration of question-asking scripting activity, on students' conceptual understanding and critical thinking in science. Generally, inquiry-based approach such as the 5Es learning approach, which is also the mode of delivery of the lesson in the present study, has been found to facilitate the improvement of student academic achievement and more importantly, facilitate the development of higher order thinking skills (Abdullah \& Shariff, 2008; Koray \& Köksal, 2009; Sadi \& Cakiroglu, 2014; Sari et al., 2017). The confluent effects of the inquiry-based approach, integration of courseware in a collaborative setting, and the question-asking scripting activity positively influence the development of conceptual understanding and critical thinking in science of students in the experimental groups. The attributes of CSCL could be analysed in terms of the computer component, in this case the integration of the courseware, as well as the collaborative aspect of learning. However, it is important to take note that the effect of the intervention is not solely due to the integration of technology where the use of courseware serves as an instructional tool in the learning process. Although, numerous literatures underscored the benefits of courseware as dynamic 
visualisation, some studies found that dynamic visualisation could also provide heavy cognitive load due to the selected complex features and transitions of frame of events (Ryoo \& Linn, 2012; Yang et al., 2018). The magnitude of cognitive load is influenced largely by the interrelatedness of the basic elements of the information that are handled at the same time by the working memory (Kalyuga \& Liu, 2015). Therefore, it can be inferred that merely integrating visualisation is not guaranteed to positively affect learning. In this light, several studies emphasised the significance of additional instructional support to facilitate analysis of lessons from visualisation platforms and existing insights (Ryoo \& Linn, 2014). The following paragraphs narrate the various elements of the intervention, such as the courseware, collaborative learning, and question-asking scripting activity. Collectively, these elements contribute to the significant influence of the teaching approach in the improvement of students' conceptual understanding and critical thinking.

Courseware is an interactive multimedia instructional material that enables students to explore science concepts through dynamic visualisations and games (Tsai, 2012). The positive effects of the integration of multimedia instructional material on learning, such as courseware, is guided by Paivo's dual coding theory wherein "learners store information received in their working memory as either verbal or visual (pictorial) mental representations" (Karacop \& Doymus, 2013, p. 188); hence, making the coding of information more authentic and longterm. With this, students can better visualise concepts, reduce the abstractness of concepts, and be able to retain information (Efendioglu, 2012; Ercan et al., 2016; Sari et al., 2019; Yang et al., 2018). These existing literatures supported the findings of the study that integration of courseware in the CSCL approaches were able to foster the improvement of students' conceptual understanding in science. Such findings were supported by the snippets from journal entries of the students, as well as by the results of focus group discussions.

CSCLTA Student 20: "The courseware helped me to increase my knowledge about volcanoes. It also helped me to experience a new way of learning. It also helped me improve my visual and auditory skills." [Acquiring new information]

QASACSCLTA Student 22: "The courseware helps visual learners since it has videos. When I am answering a test, I can easily remember the answer from the courseware." [Visual Representation Components]

Furthermore, the aforementioned features of the intervention had an impact on the improvement of the students' critical thinking skills. This result mirrors those of the previous studies that showed CSCL approaches could contribute to the development of critical thinking skills (Ada, 2009; Lin, Preston, Kharrufa, \& Kong, 2016). This was further supported by snippets obtained in the student's journal and focus group discussion which reflected how the intervention influenced the improvement of students' critical thinking and the related thinking process of such skill.

CSCLTA Student 19: "The activities are helpful, and the content is good. It helped me a lot in my critical/creative thinking because of all the things needed to be considered to accomplish the tasks." [Critical Thinking]

QASACSCLTA Student 3: "The activity helped by obtaining more information and expanding our mind. Asking questions can be challenging because it requires to think outside the box and consider other information that may not be thought of at first" [Analysis Skills]

The collaborative process contributed to the improvement of conceptual understanding and 
critical thinking. Learning collaboratively promotes collective knowledge construction that fosters knowledge internalisation and deepening which eventually affects the development of conceptual understanding and critical thinking (Shin et al., 2018). Collaborative learning can provide an environment where students are engaged in high cognitive processes like critical thinking which results in deep learning and better retention of concepts learned (Kreijns, Fischer, \& Vermeulen, 2013). In the context of the study, the researcher noticed that students in the experimental groups discussed their insights as they encountered concepts while using the courseware and as students in QASACSCLTA completed the worksheet. The discussion and explanation of information with groupmates provided opportunities to reconstruct, reevaluate, and rediscover information so as to have a more coherent and relevant understanding of the lesson. Subsequently, this could further facilitate the development of conceptual understanding and critical thinking.

Furthermore, post hoc analysis of both ESCUT and CTS consistently revealed that the only significant difference was found between the QASACSCLTA and CTA group. This implied that computer-supported collaborative learning coupled with question-asking scripting activity had a significant impact on the improvement of students' conceptual understanding and critical thinking. This is a strong indication that the innovative strategy of CSCL with question-asking scripting activity could develop a meaningful learning in science, a result that was consistent and which extended previously conducted research in CSCL (Gu, Wang, \& Mason, 2017; Shin et al., 2018).

For instance, students in QASACSCLTA were able to engage in more discussion of their ideas with their peers, especially as some contents of the courseware were contextualised. With this, students were able to learn with and through technology because of these sense-making activities that allowed students to internalise and externalise concepts. Question-asking activity allows students to extend their frame of mind and engage in complex and meaningful processing of information since students have to consider and analyse multiple perspectives (Chin \& Osborne, 2010; Huang et al., 2017; Vogel et al., 2016). This is in coherence with the Cognitive Elaboration Theory which states that one of the effective ways of learning is by explaining information with other people (Slavin as cited in Abdullah \& Shariff, 2008). In line with this, allowing students to explain concepts, such as those that happened in the questionasking activity, fosters critical thinking skills that is associated with the strengthening of conceptual understanding and applications (Heijltjes, Van Gog, Leppink, \& Paas, 2015). The various questions generated by the students reflect the way they comprehend the lesson which could be used as an indicator of their learning progress (Huang et al., 2017).

\section{Conclusion and Implications}

The findings of this present research extended previous studies and offered the synergistic innovative strategy of CSCL infused with question-asking scripting activity. The results of this investigation revealed that the CSCL was effective in developing students' conceptual understanding and critical thinking in science. Both post hoc analyses showed that QuestionAsking Scripting Activity in Computer-Supported Collaborative Learning Teaching Approach (QASACSCLTA) had a statistically significant positive effect on students' conceptual understanding and critical thinking.

The findings in this research underscore the importance of CSCL, together with questionasking scripting activity, to improve the quality of science learning by significantly improving the depth of lesson comprehension and application as well as developing critical thinking skills. 
CSCL amalgamates several approaches and its collective effect could lead to the development of collaboration, critical thinking, communication, and creativity skills which are the $21 \mathrm{st}$ century skills needed to be successful in life. Moreover, the findings of this research encourage educators to create a learning environment where students can freely construct questions that could allow them to harness their inquiring minds. This classroom setting could promote deeper learning activity, and consequently, develop higher order thinking skills and conceptual understanding. With this, educators, together with the support of the administrators, should inculcate the value of evaluation of information and asking good questions to promote life-long learning. Questioning skill is beneficial to society because such skill is considered as empirical social functioning since people with developed questioning skills are able to have reasonable analysis of the situations. Eventually, this could prompt people to do necessary actions for the betterment of the society and the environment.

This research has limitations that need to be considered. Although the findings show significant effects of the intervention to students' conceptual understanding and critical thinking in science, there is a need to replicate the same study in a larger sample size in order to increase its generalisability. Moreover, there is also one post-test to measure the conceptual understanding and critical thinking. It would be beneficial to administer delayed post-tests to have repetitive measures in order to establish the long-term effects of the intervention to the said variables. Lastly, the interaction of the students within the group is manually observed by the teacher-researcher, hence, there could be multiple interactions happening simultaneously. It would be advantageous if the performance of the group activity is being video recorded to encapsulate all the possible interactions which could be further utilised in the qualitative analysis.

Further investigation and experimentation into CSCL and questioning skills are strongly recommended. Another possible area of future research would be to investigate the fusion of CSCL with other learning approaches as it affects research variables such as collaboration skills, intrinsic and extrinsic motivation, and learning disposition. It is also worthwhile to investigate the levels of questions and trace the reasons behind these levels of question in the given lesson topics.

\section{References}

Abdullah, S., \& Shariff, A. (2008). The effects of inquiry-based computer simulation with cooperative learning on scientific thinking and conceptual understanding of gas laws. Eurasia Journal of Mathematics, Science \& Technology Education, 4(4), 387-398.

Ada, W. W. (2009). Computer-supported collaborative learning and higher order thinking skills: a case study of textile studies. Interdisciplinary Journal of E-learning and Learning Objects, 5, 145-167.

Bouyias, Y., \& Demetriadis, S. (2012). Peer-monitoring vs. micro-script fading for Enhancing knowledge acquisition when learning in computer-supported argumentation environments. Computers \& Education 59, 236-249.

Cheung, A. Slavin, R., Kim,E. \& Lake,C. (2017). Effective Secondary Science Programs: A Best-Evidence Synthesis. Journal of Research in Science Teaching, 54(1),58-81.

Chin, C. (2002). Student-generated questions: Encouraging inquisitive minds in learning science. Teaching and Learning, 23(1), 59-67.

Chin, C., \& Osborne, J. (2010). Students' Questions and Discursive Interaction: Their Impact on Argumentation During Collaborative Group Discussions in Science, Journal of Research in Science Teaching, 47 (7), 883-908.

Chan, C. K. K., Lam, I. C. K., \& Leung, R.W.H.(2012). Can collaborative Knowledge building promote both scientific process and science achievement?. International Journal on Educational Psychology, 1(3), 199-227.

Creswell, J. W. (2003). Research design: Qualitative, quantitative, and mixed methods approaches. (2nd ed.) Thousand Oaks, CA: Sage.

Efendioglu, A. (2012). Courseware development model: The effects of CDM on primary school pre-service teachers' achievements and attitudes. Computers and Education,59, 687-700. 
Ercan, O., Bilen, K., \& Ural, E. (2016). 'Earth, Sun and Moon': Computer assisted instruction in secondary school science-achievement and attitudes. Issues in Educational Research, 26(2), 206-224.

Gu, X., Wang, H., \& Mason, J. (2017). Are They Thinking Differently: A Cross-Cultural Study on the Relationship of Thinking Styles and Emerging Roles in Computer-Supported Collaborative Learning. Educational Technology \& Society, 20 (1), 13-24.

Heijltjes, A., Van Gog, T., Leppink, J., \& Paas, F. (2015). Unraveling the effects of critical thinking instructions, practice, and self-explanation on students' reasoning performance. Instructional Science, 43, 487-506.

Hofstein, A., Navon, O. Kipnis, M. \& Mamlok-Naaman, R. (2005), Developing students' ability to ask more and better questions resulting from inquiry-type chemistry laboratories. Journal of Research in Science Teaching, 42 (7), 791-806.

Huang, X., Lederman, N., \& Cai, C. (2017). Improving Chinese Junior High School Students’ Ability to Ask Critical Questions. Journal of Research in Science Teaching, 54(8), 963-987.

Kaberman, Z., \& Dori, Y.J. (2009). Metacognition in chemical education: question posing in the case-based computerized learning environment. Instructional Science, 37, 403-436.

Kalyuga, S. \& Sweller, J. (2005). Rapid dynamic assessment of expertise to improve the efficiency of adaptive elearning. Educational Technology Research and Development, 53(3), 83-93.

Karacop, A., \& Doymus, K. (2013). Effects of Jigsaw Cooperative Learning and Animation Techniques on Students' Understanding of Chemical Bonding and Their Conceptions of the Particulate Nature of Matter. Journal of Science Education and Technology, 22, 186-203.

Kirschner, P. A., \& Erkens, G. (2013). Toward a Framework for CSCL Research. Educational Psychologist, 48 (1), $1-8$.

Kollar, I., Fischer, F., Hesse, F.W. (2006) Collaboration Scripts - A Conceptual Analysis. Educational Psychology Review, 18(2), 159-185.

Koray, O., \& Köksal, M.S. (2009). The effect of creative and critical thinking based laboratory applications on creative and logical thinking abilities of prospective teachers. Asia-Pacific Forum on Science Learning and Teaching, 10(1), 1-13.

Kreijns, K., Fischer,P.A., \& Vermeulen,M. (2013). Social aspects of CSCL environments: A research of framework. Educational Psychologists, 24(4),229-242.

Lapinid, M. R. C. (2014). Evaluation of the effectiveness of CAI modules in mathematics in intermediate grade school. Retrieved from http://www.sei.dost.gov.ph/images/ts/caieval2015.pdf

Lee, Y. (2015). Facilitating critical thinking using the C-QRAC collaboration script: Enhancing science reading literacy in a computer-supported collaborative learning environment. Computers \& Education 88, 182-191.

Lin, M., Preston, A., Kharrufa, A., \& Kong, Z. (2016). Making L2 learners' reasoning skills visible: The potential of computer- supported collaborative learning environments. Thinking Skills and Creativity, 22, 303-322.

Mandernach, B. (2006). Thinking Critically about Critical Thinking: Integrating Online Tools to Promote Critical Thinking. InSight: A Journal of Scholarly Teaching. 1.

Miller, M., \& Hadwin, A. (2015). Scripting and awareness tools for regulating collaborative learning: Changing the landscape of support in CSCL. Computers in Human Behavior, 52, 573-588.

Ministry of Education. (2009). Building Conceptual Understanding in Social Sciences: Approaches to Building Conceptual Understanding. New Zealand: Crown.

Partnership for 21st century learning. (2015). Framework for 21 st century learning. Retrieved from http://www.p21.org/our-work/p21-framework

Pintrich, P. R., Smit, D. A. F., Gracia, T., \& McKeachie, W.J. (1991). A Manual for the use of Motivated Strategies for learning Questionnaire (MSLQ). Ann Arbor, MI: National Center for Research to Improve Postsecondary Teaching and Learning. University of Michigan.

Ryoo, K., \& Bedell, K. (2017). The effects of visualizations on linguistically diverse students' understanding of energy and matter in life science. Journal of Research in Science Teaching, 54(10), 1274-1301

Ryoo, K., \& Linn, M. (2012). Can dynamic visualizations improve middle school students' understanding of energy in photosynthesis? Journal of Research in Science Teaching, 49(2), 218-243.

Ryoo, K., \& Linn, M. (2014). Designing guidance for interpreting dynamic visualizations: Generating versus reading explanations. Journal of Research in Science Teaching, 51(2), 147-174.

Sadi, O., \& Cakiroglu, J. (2014). Relations of cognitive and motivational variables with students' human circulatory system achievement in traditional and learning cycle classrooms, Educational Sciences: Theory \& Practice, 14(5), 1997-2012.

Sari, U., Hassan, A., Güven, K., \& Sen, Ö. (2017). Effects of the 5E Teaching Model Using Interactive Simulation on Achievement and Attitude in Physics Education, International Journal of Innovation in Science and Mathematics Education, 25(3), 20-35.

Sari, U., Pektas, M., Celik, H., \& Kirindi, T. (2019). The Effects of Virtual and Computer Based Real Laboratory Applications on the Attitude, Motivation and Graphic Skills of University Students, International Journal of Innovation in Science and Mathematics Education, 27(1), 1-17. 
Shin, Y., Kim, D., \& Jung, J. (2018). The Effects of Representation Tool (Visible-Annotation) Types to Support Knowledge Building in Computer-Supported Collaborative Learning. Educational Technology \& Society, 21 (2), 98-110.

Shukor, N. A., Tasir, Z., Van der Meijden, H., \& Harun, J. (2014). Exploring Students' Knowledge Construction Strategies in Computer- Supported Collaborative Learning Discussions Using Sequential Analysis, Educational Technology \& Society, 17 (4), 216-228.

Sözcü, O. F. \& İpek, I. (2013). Considerations for IEl courseware design and the next generation of e-learning. European Journal of Contemporary Education, 6(4),204-215.

Stahl, G., Koschman, T., \& Suthers, D. (2006). Computer-supported collaborative learning: An historical perspective. In R. K. Sawyer (Ed.), Cambridge handbook of the learning sciences, 409-426.

Su-Chi, F., Ying-Shao, H., \& Wei, H. (2016). Effects of explicit and implicit prompts on students' inquiry practices in computer-supported learning environments in high school earth science. International Journal of Science Education, 38(11), 1699-1726.

Tsai, S. C. (2012). Integration of multimedia courseware in ESP instruction for technological purposes in higher technical education. Educational Technology \& Society, 15(2), 50-61.

Vogel, F., Wecker, C., Kollar, I., \& Fischer, F. (2016). Socio-cognitive scaffolding with computer-supported collaboration scripts: A meta-analysis. Educational Psychology Review. DOI: 10.1007/s10648-016-9361-7.

Yang, C., Jen, C., Chang, C., \& Yeh, T. (2018). Comparison of Animation and Static Picture based Instruction: Effects on Performance and Cognitive Load for Learning Genetics. Educational Technology \& Society, 21 (4), $1-11$. 